\title{
Theorizing Artificial Intelligence Acceptance and Digital Entrepreneurship
}

\section{Model}

\section{Dr. Nitin Upadhyay [Corresponding author]}

Chairperson Integrated Program in Management

IT Systems and Analytics

Indian Institute of Management Jammu

Jammu-180016

Email: upadhyay.nitin@gmail.com,nitin@iimj.ac.in

Dr. Shalini Upadhyay,

Associate Professor, Humanities and Social Science Department, BITS Pilani K K Birla Goa Campus, Goa, 403726, India

Email: shaliniu@goa.bits-pilani.ac.in

Prof. Yogesh K. Dwivedi, PhD

School of Management Swansea University Bay Campus, Fabian Way, Swansea, SA1 8EN

Email:y.k.dwivedi@swansea.ac.uk

\begin{abstract}
:
Purpose: This paper aims to determine the entrepreneur's intention to accept artificial intelligence (AI) and provide advancement in the domain of digital entrepreneurship.

Design/methodology/approach - Extensive literature review and theories have been considered in the area of technology adoption/acceptance and digital entrepreneurship to identify the factors affecting the intention of entrepreneur's w.r.t to accept AI for digital entrepreneurship. Further, a model, artificial intelligence acceptance and digital entrepreneurship (AIADE) is theorized after formulating some hypotheses. The theorized model has been validated with 476 usable responses.
\end{abstract}

Findings: The findings revealed that performance expectancy, openness, social influence, hedonic motivations, and generativity have a positive impact on entrepreneur's acceptance intention of AI. Additionally, affordance has no direct relationship with AI acceptance 
intention, but it affects AI acceptance intention through Attitude. Inconvenience has a significant negative relationship with the intention to accept AI, while uncertainty was found to be positively affecting the AI acceptance intention. Effort expectancy did not confirm any significant relationship.

Research limitations/implications: By considering existing theoretical models and concepts we contribute to the AI's theoretical progress, specifically in the domain of entrepreneurship. We complement and extend existing technology adoption/acceptance theories and digital entrepreneurship theories by developing a theoretical model, artificial intelligence acceptance and digital entrepreneurship, explaining the entrepreneur's intention to accept AI.

Practical implications - The practical implications of the study show that performance expectancy (positive), openness (positive), social influence (positive), hedonic motivations (positive), generativity (positive), affordance through Attitude (positive), uncertainty (positive), effort expectancy (negative) and inconvenience (negative) are the antecedents for the entrepreneurs to accept AI for digital entrepreneurship. We suggest that intentional improvement planning is developed by increasing entrepreneur's positive perceptions of AI affordance and explanation of its generativity and openness, and improving their attitude of using AI for digital entrepreneurship.

Originality/value: This is the first study that reveals the critical antecedents of entrepreneur's intention to accept AI for digital entrepreneurship. Relevant theoretical background, discussion, implications, limitations, and future research recommendations are discussed.

Keywords Entrepreneurship, Technology acceptance, Digital entrepreneurship, Artificial intelligence, Entrepreneur intention

\section{Paper type Research paper}




\section{Introduction}

Digital technologies and tech-generation enable new business models, ventures, and operations to make societies and institutions more inclusive, transparent, and accountable (Pinker, 2018). In the last decade, many new technology trends have emerged resulting in appreciation of emerging technologies such as artificial intelligence, big data, cloud and internet of things (European Commission, 2017) which have initiated novel ways of collaboration, coordination, and innovation and competition. Such technological developments are reshaping traditional businesses, models, strategies, and operations (Bag et al., 2021; Bharadwaj et al., 2013; Balakrishnan \& Dwivedi, 2021; Borges et al., 2021; Demlehner et al., 2021; Dubey et al., 2021; Dwivedi et al., 2020; Grover et al., 2020; Pillai et al., 2020; 2021; Zhang et al., 2021; Shareef et al., 2021). Undoubtedly, digital technologies are considered as the enablers for the activities related to entrepreneurial process, outcome and innovation (von Briel et al., 2018), leading to manifestation in various forms. For example, manifestations can be in the form of digital artefacts (Ekbia, 2009), digital platforms (Tiwana, 2014), digital products or services (Lyytinen et al., 2016), digital tools or infrastructure (Aldrich, 2014), or digital product or service innovations (Kuester et al., 2018).

Murphy et al. (2006) argue that entrepreneurship is the key driver for economic changes and industry transformation. Additionally, digital technologies and entrepreneurship's convergence provide new avenues for developing entrepreneurial projects and ventures (Anderson, 2014; Giones \& Brem, 2017). As the digitalization phenomenon results into several vital implications, entrepreneurs and entrepreneurship researchers need to be aware of potential usage, outcomes and associated opportunities. Due to the emergence of the digitalization phenomenon, "digital entrepreneurship" is considered a novel form of entrepreneurial activities. Scholars and practitioners believe artificial intelligence technology is a groundbreaking technology that disrupts businesses, business activities, markets, and competition 
(Dwivedi et al. 2021). Even dominancy of AI outcomes in the innovation and disruption space is considered to be of significant magnitude as compared to any other known technology (Makridakis, 2017). Entrepreneurs see viable and potential opportunities to use artificial intelligence at every market level (Marr \& Ward, 2019). However, certain factors affect the acceptance of artificial intelligence by entrepreneurs. Entrepreneurship research has limited exposure in exploring and understanding entrepreneurs' intentions to use artificial intelligence in digital entrepreneurship. As such, novel theorizing on digital entrepreneurship and intentions to accept artificial intelligence is indeed required (Nambisan et al., 2017; Nambisan, Wright, \& Feldman, 2019b; Sussan and Acs, 2017).

We aim to explore the motivation behind the entrepreneur's intention to accept artificial intelligence (AI). We propose to advance AI's theoretical progress (Dwivedi et al. 2021; Duan, Edwards \& Dwivedi, 2019), specifically in the domain of entrepreneurship. We complement and extend existing technology adoption/acceptance theories (Dwivedi et al., 2017; 2019; Kwonsang, and Ohbyung, 2020; Venkatesh et al. 2012) and digital entrepreneurship theories (Nambisan, 2017; Nambisan, Wright, \& Feldman, 2019b; Chalmers, MacKenzie, \& Carter, 2020) by developing a theoretical model, Artificial Intelligence Acceptance and Digital Entrepreneurship (AIADE), explaining the entrepreneur's intention to accept AI. The paper aims to identify the potential factors impacting the entrepreneur's intentions to accept artificial intelligence.

The current AI literature mostly focuses on the status, gaps, and improvements in employment related to skilled and unskilled workforce (The World Bank, 2019). However, there is a need to understand the effect of novel technological affordances and entrepreneurs attitude on their intention to adopt artificial intelligence (Obschonka \& Audretsch, 2019; Townsend \& Hunt, 2019). Despite the advocacy of AI adoption and its applicability in the firm's increased 
performance, little has been contributed in the literature about the AI-digital entrepreneurship intersection (e.g., Liebregts et al., 2019; Townsend \& Hunt, 2019). We, therefore, propose several contributions to the emerging AI-digital entrepreneurship intersection. Firstly, we explore the concept of emerging AI-digital entrepreneurship intersection. Secondly, we examine critical factors contributing to the acceptance of AI by entrepreneurs. Finally, we identify a valuable stream of research, and insights on the AI-digital entrepreneurship intersection landscape.

\section{Theoretical Background}

\subsection{Digital Entrepreneurship}

According to Anderson (2014), potent entrepreneurial projects have resulted from the diffusion of digital technologies where entrepreneurial activities leverage collaboration and collective intelligence. Such convergence develops new avenues for venture (Giones \& Brem, 2017). Entrepreneurship goes beyond realizing new value creation by streamlining designing, launching, and executing entrepreneurial activities and business processes for business ventures and business values (Hull et al., 2007, Hsieh and Wu, 2018). By leveraging digital technologies, many business ventures alter their business processes, operations, and solutions from offline to online- resulting in "digital entrepreneurship" as a novel branch of entrepreneurial activities. In this paper, "digital entrepreneurship" is positioned as entrepreneurship's subcategory. It deals with digitizing some or all part of entrepreneurial activities, processes, and operations to transfer an asset, services, or significant part of the business into digital (Hull et al., 2007, Le Dinh et al., 2018). Digital entrepreneurship orient towards digitizing most or all of a business's products and services to offer new and unique value (Hull et al., 2007). Sussan and Acs (2017) advocate the use of digital technologies as part of the core competency to develop products and services for digital entrepreneurship 
customers. Besides, digital technology facilitates connections and collaborations of people, machines, and information (The Guardian, 2017). According to Nambisan (2017), entrepreneurial pursuits have limited or less exposure of digital technologies in entrepreneurial research and practice. However, current research on digital entrepreneurship has not advanced and still seems to be in infancy (Kraus et al., 2019). The motivation of entrepreneurs' intention of digital technologies is vital to understand digital entrepreneurship success.

\subsection{Artificial Intelligence-Digital Entrepreneurship Intersection}

Digital technologies are pushing digital entrepreneurship at the edge in redefining and reshaping business and communication. Emerging technologies such as artificial intelligence, big data, cloud and internet of things foster new platforms and development paradigm for building new and novel products and services (Le Dinh, 2018). Scholars and practitioners consider the technology of artificial intelligence (AI) as a ground-breaking technology that can change the dynamics of the markets, businesses, industries, and pursue entrepreneurial activities (Von Briel, Davidsson, \& Recker, 2018). Additionally, its disruption, innovation, and value offerings are considered of great magnitude compared to any other existing technology (Marr and Ward 2019; Makridakis, 2017). AI has already disrupted many business activities and penetrated diverse areas of everyday life. For example, suggestion for shopping, face and voice recognition, or digital assistants (Intel Corporation, 2020) are prominent solutions.

Additionally, AI technology is considered vital in diverse digital entrepreneurship areas such as medical technologies, retail, manufacturing, and other businesses. For example, AI is utilized for diagnosis of medical conditions (Cockburn et al. 2018), providing health care (Augusto et al. 2007), supporting applications for intensive care unit (Hanson and Marshall 2001), developing structured webshops, bots both for in-shop and online interaction, attaining proactive preventive maintenance solutions and services for machines. Even AI is potent to 
offer product-as-service business models. AI can be distinguished into two forms - symbolic AI and neural-AI. In a symbolic AI, to facilitate rule-based thinking, symbols are utilized as the core elements to trigger the program's learning process. Business organizations consider symbolic AI a support system as it's process and logic are quite easily understandable and practicable for human users. Typically, symbolic AI is heavily used in streamlining the automation of the business processes, tasks, activities, and operations. While the neural-AI deals with the self-learning algorithm that learns by itself based on the sample/practice data for generating patterns (Skilton \& Hovsepian 2018, pp. 132-134). Such patterns are then improvised based on any unknown data or used to decipher the situation or environment. The sample/practice data sources are vital for neural-AI to develop an effective algorithm that can perform well on the unforeseen data, situation, and environment (Lee et al. 2019, p. 4). An entrepreneur must have clarity on both the technological and business perspective of AI. Besides, considering it as an outcome-driven engine for the business can open potential opportunities. For example, entrepreneurs keen on using AI can view it as a prediction machine that helps to focus on the outcome - past, current, and future. The entrepreneurs should understand both the technological and practicable AI interpretation while using it or consider using it in the future (Agrawal et al., 2018).

Entrepreneurs have recently shown interest in AI to streamline, (re)define, and (re)shape business activities, operations, and values. Shane (2000) argues that AI provides immense potential at all stages of the entrepreneurial process. For example, AI can facilitate quick venture creation process by expediting data collection, market and feasibility study in the exploration phase; and streamlining positioning and market targeting process in the exploitation phase. Entrepreneurs facing a resource-constrained environment benefit by using AI to exploit their machine learning capabilities to automate tasks and deploy models for 
managing entrepreneurial activities and engagements. McMullen \& Shepherd (2006) observe that by exploiting big data and AI, one can avoid uncertainties in the entrepreneurial process.

Agrawal et al., (2018) argue that AI can impact the firm's strategy and business models. Besides, AI provides strategic implications to digital entrepreneurship by assisting, supporting, and driving business models for new and old organizations. Entrepreneurs keen on using AI must understand and explore the utility and impact of AI-assisted, AI-supported, and AI-driven functionalities. The AI-assisted functionality affects the business models' operational activities and does not directly impact the business models' strategic aspects and components. Here, few or more business processes undergo improvisation. The AI-supported functionality directly affects one or more components of the business models and thus has a strategic impact on the business. While the AI-driven functionality enables the development of a new business model to create, generate, and deliver values. Figure 1 depicts the increasing influence of AI. Entrepreneurs can unlock variations in business models through AI to enhance business value in venture creation (Loebbecke \& Picot, 2015; Lee et al., 2019).

<<Insert Figure 1. Increasing influence of AI in digital entrepreneurship >>

\subsection{Artificial Intelligence acceptance by entrepreneur's for digital entrepreneurship}

This study is concerned with the motivation of the entrepreneur's intention to adopt/accept AI. In this context, it is important to mention here that entrepreneur actors are responsible for translating AI adoption for digital entrepreneurship. It is vital to understand and explore the existing research in technology acceptance and adapt or compliment them for digital entrepreneurship. Digital entrepreneurship depends on digital technologies' three main factorsopenness, affordance, and generativity (Nambisan, 2017; Nambisan \& Baron, 2019; Nambisan, Wright, \& Feldman, 2019b; Chalmers, MacKenzie, \& Carter, 2020). The factor "openness" deals with varied aspects of digital technology. For example, what is the level of participation 
of the actors (who all can participate); what all contributions can actors make (what inputs actors can provide); how actors can contribute (What processes are utilized to contribute) and lastly, what outcomes are attained (what contributions are mapped to the outcomes). As such, digital technologies' level of "openness" capability for participation, contribution, and outcomes determine entrepreneurship innovation (Rothwell et. al., 1974). Another factor, "affordance" associated with digital technologies is considered for digital entrepreneurship. It depicts the aspect of an object to offer certain action potential and possibilities to an actor in a specific context. For example, AI technology in digital entrepreneurship can be affected by its affordances (Faraj and Azad, 2012; Gibson, 1979). Finally, the Generativity factor of the digital technology is its capability to produce unprompted change by involving large unrelated and uncoordinated entities/actors. (Doanld, 1991; Turner \& Fauconnier, 1997). As such, AI technology generativity in digital entrepreneurship determines entrepreneurship innovation.

AI is considered a disruptive and innovative technology that can enhance an organization's or an individual's productivity and competitiveness. Currently, two branches of research are available related to technology acceptance. Firstly, the research focuses on the relevant factors required for adopting technology at the organization's level (Leonard-Barton and Deschamps, 1988). Technology, organization, and environment (TOE) framework (Tornatzky and Fleischer, 1990) and diffusion of innovation (DOI) theory (Rogers, 2003) are the prominent theoretical models work at the firm level. DOI theory considers individuals as prime for the level of willingness to adopt innovation and presses the organization innovativeness dependency on both internal and external characteristics. While, the TOE framework deals with determinants related to technological, organizational, and environmental contexts for technological innovation adoption. The second approach deals with the individual level. In this approach, usage or intention to adopt the technology is considered as the dependent variable (Davis et al., 1989; Compeau \& Higgins, 1995). The current study explores the intentions of 
the entrepreneurs to accept artificial intelligence. Hence it focuses on individual's intention of acceptance of technology. Therefore, the undertaken study focuses on individual's intention of acceptance of technology. Many prominent models exist in this space such as - Motivational model (MM), Unified theory of acceptance and use of technology (UTAUT),Technology acceptance model (TAM), and Theory of planned behaviour (TPB), that have been extensively referred and utilized by researchers to assess and analyse the individual level technology adoption. Constructs such as ease of use and observed usefulness are considered vital for the TAM (Davis, 1989). The MM model considers extrinsic and intrinsic motivations as the core constructs and is essential for technology adoption (Ajzen, 1991). Attitude is considered a vital construct in TPB, an extension of the theory of reasoned action (TRA). The core constructs in the UTAUT model (Venkatesh et al., 2003) are social influence, facilitating conditions, performance expectancy, and effort expectancy.

Individuals get confidence with the performance expectancy that technology helps them enhance productivity and complete the task quickly. The construct effort expectancy deals with the belief that the technology or system would be clearly understood, which will help in easy use. Social influence is the belief to improve the use of the system or technology by being in a group that can influence the individuals. The other construct facilitating conditions deals with the availability of resources, and knowledge which are considered vital for technology adoption. However, technology affordance captures such purview and extends its capability to cover technology possibilities (Faraj \& Azad, 2012). Uncertainty is attributed to decision maker's perception of the technology or system in context considering the environment and affects the decision to roll out new product/service or use new technology (Ghosh \& Bhowmick, 2014). Additionally, individuals' inconvenience in using technology or system adversely affects its usage (Collier and Kim, 2013). Hedonic motivation impacts the adoption of digital technologies (Tamilmani et al., 2019; Van Der Heijden, 2004). It depicts intrinsic 
motivations such as the perception of fun, entertainment, and individuals' enjoyment to try new technology products. Many empirical studies based on TRA and the theory of planned behavior (TPA) model have confirmed impact of attitude on technology adoption intention.

\section{Research framework and hypotheses}

The undertaken research focuses on the entrepreneur's intention to accept AI for digital entrepreneurship. It is also paramount that entrepreneur actors be responsible for translating AI adoption/acceptance for digital entrepreneurship. Hence, it focuses on an individual's intention of acceptance of the technology. In this context, the current study explores the AI-digital entrepreneurship intersection, identifies relevant constructs, and develops a framework that explains entrepreneur's intention to accept artificial intelligence. It is vital to understand and explore the existing research in technology acceptance and adapt or complement them for digital entrepreneurship. Digital entrepreneurship depends on digital technologies' three main factors- openness, affordance, and generativity (Nambisan, 2017; Nambisan \& Baron, 2019; Nambisan, Wright, \& Feldman, 2019b; Chalmers, MacKenzie, \& Carter, 2020). Based on the theoretical models and concept discussed in Section 2, we consider ten constructs in this study that affects intention of entrepreneur's to accept AI. Table 1 describes the antecedents for the intention of the entrepreneur's to accept artificial intelligence. These antecedents are grounded on the in-depth literature review.

$<<$ Insert Table 1 Antecedents for the intention of the entrepreneur's to accept artificial intelligence >

\section{Performance expectancy}

Performance expectancy is an important factor influencing the entrepreneurs to use AI to attain expected performance for entrepreneurial projects and activities. Venkatesh et al., (2003) 
define it as "the degree to which an individual believes that using the system will help him or her attain gains in job performance". Venkatesh et al. (2003) advocate performance expectancy as the most decisive factor influencing users' intention to use any new system or technology. In this study, performance expectancy encompasses the AI usage in supporting, assisting and driving entrepreneurial projects and digital entrepreneurship activities. Agrawal et al. (2018) observe that AI technology can provide strategic implications to digital entrepreneurship by assisting, supporting, and driving business models for new and old organizations. Based on the discussion, following hypothesis is proposed:

H1: entrepreneurs' performance expectancy of AI for digital entrepreneurship is positively associated with their AI acceptance intention.

\section{Effort expectancy}

Effort expectancy depicts the effort required by users'. It is the degree of ease of use for technology or system (Venkatesh et al., 2003). It refers to the perceived convenience of ease of use associated with a new information system or technology. Aggelidis and Chatzoglou (2009) argue effort expectancy affects users' behavioral intention to use a new system or technology. Entrepreneurs tend to consider the use of a system and technology when they perceive less effort expectancy in handling it. Moreover, perceived less effort expectancy in dealing with technology or system triggers a sense of having improved user performance. Entrepreneurs get motivated to use a system or a technology when they feel that it requires less effort to attain entrepreneurial projects and activities. Nonetheless, it is reasonable to expect that entrepreneurs will tend to use less AI who think that AI is complex. The following hypothesis is proposed: 
H2: entrepreneurs' effort expectancy of AI for digital entrepreneurship is positively associated with their AI acceptance intention.

\section{Social influence}

Social Influence depicts the degree to which users perceive what other important people believe or advocate using a new system or a technology. Venkatesh et al. (2012) observe that social influence captures subjective norms dealing with how an individual's behaviour is affected by an important person's influence. In this research, social influence refers to the entrepreneur's perceived encouragement and influence from its reference and network. When entrepreneurs observe successful projects and activities using new technology in their influential network, they tend to adopt and experiment the technology. Based on the discussion, following hypothesis is proposed:

H3: entrepreneurs' social influence for AI in digital entrepreneurship is positively associated with their AI acceptance intention.

\section{Hedonic Motivation}

Hedonic motivation refers to how a user's perception about the use of a system or technology will bring pleasure (Lee et al., 2003). Entrepreneurs are strongly driven by intrinsic motivation (Deci, Koestner, \& Ryan, 1999) to use the system or technology to perform entrepreneurial projects and activities. Hedonic motivations are related to the incentive of the users' behaviour involving in an activity with an intangible outcome. As such, users tend to autonomously indulge in activities (Deci \& Ryan, 1985). The hedonic motivation determines adoption for using digital technologies (Van Der Heijden, 2004). Based on the discussion, following hypothesis is proposed: 
H4: entrepreneurs' hedonic motivations for AI in digital entrepreneurship are positively associated with their AI acceptance intention.

\section{Inconvenience}

The proliferation of AI libraries, tools and services might posit a perception that individuals can conveniently deal with AI. However, as suggested by Hill et al. (2015) finding appropriate technology solution in context require both expression and intention requirement confirmation. Collier and Kim (2013) suggest self-service assistant integration and usage in AI solution affect its usage adversely when it is inconvenient for individual to use AI appropriately. As such, entrepreneurs who intend to deal with AI for potential solutions and services are adversely affected if they find any inconvenience with it. The following hypothesis is proposed based on this discussion:

H5: entrepreneurs' inconvenience of using AI in digital entrepreneurship is negatively associated with their AI acceptance intention.

\section{Uncertainty}

New product development and technology advancements are affected by the uncertainty (Song, and Montoya-Weiss, 2001; Halaweh, 2013). Previous studies indicate that various entrepreneurial activities such as adopting new technology, developing new products and offerings to the market get affected by market uncertainty (Hall et al., 2011; Hu et al., 2011). AI is predominantly explored for automation and several academic and practice articles emphasize disruption of job and workforce (Pol \& Reveley, 2017; Akst, 2013). As such, individuals who intend to use AI for such offerings are reluctant to use it due to perceived uncertainty of the market for widespread adoption of the solutions. Additionally, entrepreneurs 
might avoid such technological ventures where market uncertainty is prevalent. The following hypothesis is proposed based on this discussion:

H6: entrepreneurs' uncertainty of using AI automation in digital entrepreneurship is negatively associated with their AI acceptance intention.

\section{Openness}

The openness refers to the technology's features and functionality to facilitate actors' participation, contribution, process, and outcomes. Digital technologies support openness in a variety of ways such as digital resources (Kallinikos et al., 2013, p359), technological architecture to support digital platforms (Tiwana, 2014) and technological ecosystem to facilitate collaboration, governance and joint decision making (Wareham et al., 2014). An entrepreneurial innovation can be enhanced by leveraging the openness of the technology. AI has been instrumental in entrepreneurial innovation and laying the foundation for entrepreneurial projects and activities. Besides, it is causing transformation in both scale and degree in openness. AI-assisted, AI-supported and AI-driven platforms and ecosystems benefit individuals, organizations as well as the broader society. For example, AI platforms that track and monitor healthcare data potentially benefit many stakeholders and trigger collaboration, decision making, and collective governance. Based on the discussion, following hypothesis is proposed:

H7: Openness of AI in digital entrepreneurship is positively associated with entrepreneurs' acceptance intention of AI.

\section{Affordance}


Affordance deals with the action potential and possibilities offered by the object to the user (or in a use context). Entrepreneurial projects and activities are affected by affordances when entrepreneurs use a certain system or technology. Faraj and Azad (2012) observe affordance as the vital factor for technology adoption in rolling out services, solutions and ventures. Nambisan (2017, 2019a,b) argue that same digital artefact, digital platform or digital infrastructure result in varied outcomes based on use contexts. A digital technology affordance is associated with features and functionalities of a digital platform and digital infrastructure to support service, products, and solutions. For example, AI-assisted, AI-supported and AI-driven services, products, and solutions can have a varied impact to business considering use context. Emerging technologies such as AI redefines relationships among objects and entities and thus have implication in use context. Based on the discussion, following hypothesis is proposed:

H8: Affordance of AI in digital entrepreneurship is positively associated with entrepreneurs' acceptance intention of AI.

\section{Attitude}

Attitude refers to the degree of an individual's liking or feeling of a particular behaviour. Existing studies argue that a user's adoption of digital technology is affected by his/her positive attitude no matter how sophisticated is the technology (Dwivedi et al., 2007; 2017; 2019; Dwivedi, \& Weerakkody, 2007; Huang and Liaw, 2005). Fulantelli and Allegra (2003) observe a weak positive attitude by SME entrepreneurs in adopting ICT for their business due to ICT security concerns. Bandura (1982) observes a greater sense of attitude when system is perceived affordable. AI services and applications development, execution, and deployment require $\mathrm{AI}$ affordance of knowledge and resources resulting in the desired outcomes which 
affect an individual's Attitude. As such, affordance to develop, run, and deploy AI models affects entrepreneurs Attitude to use AI to support, assist, and drive entrepreneurial projects and digital entrepreneurship activities. Attitude influences the intention of users to use something new. Entrepreneurs indulge in entrepreneurial projects and activities when they showcase a positive attitude. Xavier, Vieira \& Rodrigues (2009) argue that entrepreneurs should have a positive attitude towards new technology or system to develop products, services, and establish ventures. Thus, Attitude towards AI affordance could mediate the entrepreneurs' propensity to experiment with AI and the intention to use it. The following hypotheses are proposed based on this discussion:

H9a: Affordance of AI in digital entrepreneurship is positively associated with entrepreneurs' Attitude towards AI.

H9b: entrepreneurs' attitude for AI in digital entrepreneurship is positively associated with their AI acceptance intention.

\section{Generativity}

The Generativity factor of the digital technology is its capability to produce unprompted change by involving large unrelated and uncoordinated entities/actors (Doanld, 1991; Turner \& Fauconnier, 1997). Zittrain $(2006,2008)$ argue that technology generativity contributes to both creative and entrepreneurial endeavors. Scholars have attributed several characteristics and mechanisms of digital transformation, artifacts, technologies, and infrastructures to project generativity (Tilson et al., 2010; Yoo et al., 2012; Lyytinen et al., 2017). For example, AIdriven platforms can provide several heterogeneous APIs to third-party developers to create new digital artefacts, products, and services. Such platforms also lead to entrepreneurial 
innovation. AI can impose several implications on generativity due to data, privacy and security laws, IP rights etc. As such, AI technology generativity in digital entrepreneurship is critical and following hypothesis is proposed:

H10: Generativity of AI in digital entrepreneurship is positively associated with entrepreneurs' acceptance intention of AI.

Figure 2 depicts the Artificial Intelligence Acceptance and Digital Entrepreneurship (AIADE) model explaining the entrepreneur's intention to accept AI.

$<<$ Insert Figure 2. Artificial Intelligence Acceptance and Digital Entrepreneurship (AIADE) model >

We consider PLS-SEM approach to statistically test and validate the hypotheses and the AIADE model as it is considered effective for synthesizing an exploratory study like this (Hair et al., 2018). PLS-SEM works effectively to test the complex model without any sample restriction (Willaby et al., 2015).

\subsection{Measurement instruments}

We develop the set of questions considering the constructs, see Table 1. With the concept of the constructs, we prepared 38 questions. The questions were framed and adapted with a aim to eliminate confusing, controversial, or leading questions. The Table 2 represents the source of the constructs. We formulated the scales for inconvenience, openness, affordance, and generativity based on the theoretical concepts. Further, we consulted five experts in digital entrepreneurship and AI to examine and validate the readability, validity, understandability, and comprehensiveness of the questions. All these meticulous attempts were taken to enhance the response rate (Harzing et al., 2012). The purpose of the survey design was to capture the 
entrepreneur's intention to accept AI for digital entrepreneurship. As such, we ensured that the survey questions are readable, crisp, precise, and understandable. (Mellahi and Harris, 2016). Each question response is collected on the 7-point Likert scale on the level of agreement. The survey also encompasses guidelines to fill the survey response to avoid any misunderstanding. A precise set of instructions and note about the purpose of the study, data collection, assurance of the respondents' confidentiality and anonymity were mentioned (Chidlow et al., 2015).

$<<$ Insert Table 2 Source of constructs $>>$

\subsection{Data Collection and Sample}

Initially, a pilot survey was conducted with seven participants to capture the survey's completeness and correctness. Not much modification was made barring except a few corrections in spelling mistakes and layout. Online channel is considered the most appropriate channel to gather the survey information as it does not have space and time barrier (Evans \& Mathur, 2018; Couper 2017; Selm, 2006; Evans \& Mathur, 2005). The survey was floated on various prominent online channels targeting different AI entrepreneurship-focused groups. Apart from that, mailing lists focused on intranet posts, and targeted email groups in the author's business network have also been used for survey distribution. Ilieva, Baron, and Healey (2002) suggest that online surveys' average response time is 5.59 days. Considering the slack time due to Pandemic (COVID-19), the survey was kept online for 21 days.

We initially received inputs from 509 respondents, out of which 476 forms were complete. Since the survey was distributed through the online channel, we checked for a non-responsive bias using normality, kurtosis and skewness of the differences and performed t-tests to verify the means of early respondents and late respondents as recommended by Armstrong and Overton (1977). However, we did not observe any significant difference in the early and the 
late responses. Thus, non-responsive bias risk was considered as low. The final sample size of 476 was considered for further analyses, which were within the acceptable range (Deb \& David, 2014).

Table 3 depicts the demographic characteristics such as gender, age, education, marriage status and country of 476 respondents. Sample represents that $74.78 \%$ of the respondents are male while $25.21 \%$ are female. Respondents aged between 31 and 35 years $(27.73 \%)$, and 36 and 40 $(25.42 \%)$ represented $52.25 \%$ of the total sample. Respondents aged between 25 and 30 years represented $19.95 \%$ of the sample, whilst respondents aged between 18 and 24 years represented only $8.19 \%$ of the sample. Finally, respondents aged above 40 years represented $18.69 \%$ of the sample. The respondents are dominated by those who have bachelor's degree as the majority respondents (i.e. $65.33 \%$ ) held bachelor's degree, while $25 \%$ of the respondents pursued master degree course and $6.09 \%$ of the respondents held doctorate degree. Only $3.57 \%$ of the respondents were senior high school graduate. Additionally, $61.13 \%$ of the respondents are married, while $38.86 \%$ of the respondents are single. Table 3 also represents the countrywise distribution of the respondents. Respondents from the USA (15.34\%), China (13.45\%), UK(11.55), and Italy (9.45) represent 50\% of the total sample. Whilst respondents from Russia (8.40\%), France (7.56\%), Germany (7.35\%), India (6.93\%), Australia (5.88\%), Spain( $5.67 \%)$, Netherlands (4.41), and Canada (3.99) contribute to the $50 \%$ of the total sample.

$<<$ Insert Table 3 Demographic characteristics $(\mathrm{n}=476)>>$

PLS-SEM analysis was conducted using SmartPLS 3.3.2 software to verify the proposed theoretical model and hypotheses (Ringle, Wende \& Becker, 2015). The analysis of the measurement model was accomplished considering the construct's reliability and validity. Several parameters were considered to analyse the structural model, such as $\mathrm{R}^{2}$, path coefficients, and confidence intervals (Henseler, Hubona \& Ray, 2016). Additionally, for 
assessing the model fit, value of Goodness of Fit $(\mathrm{GoF})$ and other prominent factor standardized root mean square residual (SRMR) were used as the potential measures (Tenenhaus et al., 2005; Henseler, Hubona \& Ray, 2016).

\section{Results}

Table 4 shows the assessment of the measurement model. The loading factors of each indicator of the construct are measured to assess each indicator's convergent validity. Carmines \& Zeller, (1979) suggest considering indicators having value more than 0.7. Except one indicator of the construct Inconvenience, which is dropped due to resultant value less than 0.7 , all the other indicators are considered for further analysis. As indicated in Table 4, the AVE value of the latent variables exceeds 0.5 , all of them attained convergent validity. Additionally, on scrutiny, Cronbach's alpha and composite reliability values are identified well above the minimum-cut off range (Fornell \& Larcker, 1981). Discriminant validity shows the uniqueness of the constructs with others in the model. Vuong and Sid (2020) advocate use of Fornell-Larcker criterion to determine the discriminant validity of latent variables. Fornell and Larcker (1981) suggest that discriminant validity is observed when each latent variable's square root is higher than all correlations. While observing carefully, we found that discriminant validity was established as all the correlations were less than the square roots of the AVEs, Table 5. Thus, the measurement model was confirmed satisfactory.

<<Insert Table 4. Measurement model assessment >> $<<$ Insert Table 5. Discriminant validity results $>>$

\subsection{Structural model assessment}

The model shows the absence of multicollinearity as the VIF values of all the endogenous constructs' variables are found to be less than 5. Figure 3 depicts the overall analysis. We 
performed Harman's single factor test to check for common method bias. We did not find any single factor that captures the variance as we observed almost $69.50 \%$ of the variance that was captured by nine factors. Even the first factor only captured almost $24.11 \%$ of the variance which is less than the threshold value (Podsakoff et al., 2003). Thus, we confirm that CMB did not distort results. The estimates of the relationships of the structural model are captured through path coefficients. The effects significance are attained through bootstrapping (Hair et al. 2011) considering 5000 samples (Streukens \& Leroi-Werelds, 2016) and a 1-tail T statistics accounting n-1 degrees of freedom. The hypotheses have specified the relationships direction of the variables. Additionally, the confidence intervals were used to assess the significance of the relationships. We can observe from Table 6 and Figure 3 that the construct Performance Expectancy construct has the highest significant impact on AI acceptance intention (H1: $\mathrm{PE} \rightarrow \mathrm{AIAI} ; \beta=0.325, p<0.0001)$.

<<Insert Table 6. Hypothesis testing results $>>$

The construct Openness is also depicting the high effect on AIAI (H7: OP $\rightarrow$ AIAI; $\beta=0.151$, $p<0.0001)$. Additionally, the constructs Social influence (H3: $\mathrm{SI} \rightarrow \mathrm{AIAI} ; \beta=0.114, p<0.0001)$ and Hedonic Motivation (H4: $\mathrm{HM} \rightarrow \mathrm{AIAI} ; \beta=0.113, p<0.0001)$ also depicts the high effect on AIAI. Besides, the construct Inconvenience (H5: IN $\rightarrow$ AIAI; $\beta=-0.138, p<0.0001)$ indicates the negative high effect on AIAI as hypothesized. A weak but a significant relationship between Generativity and AIAI (H10: GE $\rightarrow$ AIAI; $\beta=0.074, p<0.0001)$ is observed. The relationship between Affordance and AIAI is not confirmed (H8:ns), while it affects AIAI through the construct Attitude having indirect relationship (H9a: $\mathrm{AF} \rightarrow \mathrm{AT} ; \beta=$ 0.681, $p<0.0001$, H9b: AT $\rightarrow$ AIAI; $\beta=0.185, p<0.0001)$. The relationship between the construct Effort Expectancy and AIAI is not confirmed (H2:ns). A contrary, direct and positive, relationship between Uncertainty and AIAI is observed (H6: $\mathrm{UN} \rightarrow \mathrm{AIAI} ; \beta=0.131, p<0.0001$ ). 
The variance of the construct is depicted through the value of $\mathrm{R}^{2}$ and the explanation of the same is achieved by the predictor variables of the endogenous construct of the model. In the theorized model, the variance is explained through AIAI (49.4\%) and AT (46.5\%). The values of SRMR and GoF were found to be 0.58 and 0.047 respectively, which are under the specified threshold for assessing the model fit (Henseler et al., 2014; Hu and Bentler, 1998).

$<<$ Insert Figure 3. AI acceptance intention results ${ }^{*} \mathrm{p}<0.05 ;{ }^{* *} \mathrm{p}<0.01 ; * * \mathrm{p}<0.00$; ns: non-significant $>>$

\section{Discussion}

The study focuses in determining the antecedents for entrepreneur's intention to accept artificial intelligence for digital entrepreneurship. Goswami and Dutta, (2016) observe the significance of PE and SI for the entrepreneurs' acceptance of emerging technology. Entrepreneurs expect a significant technological performance level to solve the tasks, activities, and problems to roll out services, offerings, and solutions. As such the performance expectancy becomes more relevant. Moghavvemi, Salleh and Standing (2016) support the importance of PE, SI, and HM in the study conducted on 1200 entrepreneurs for examining intention to adopt and use innovative technology. The entrepreneurs keen on establishing a new venture using innovative technology are found to be driven by PE, SI, and HM. Besides, HM drives the entrepreneur's motivation to try technology when it substantially solves the problems. When people enjoy using technology, entrepreneur's help offering innovative solutions that demonstrate achieving pleasurable objectives (Bilton, 2015; Woods, 2018). SI also explains the AI acceptance intention. Entrepreneurs who are influenced by people who use technology either to offer or use solutions are found to be demonstrating high level of technology acceptance (Moghavvemi, Salleh \& Standing, 2016). Nägle and Schmidt (2012) observe no relationship between intention and EE. A study conducted on entrepreneurs by Macedo (2017) 
determines a positive relationship between EE and the intention to use technology. Our findings for PE, SI, EE, HM and EE support the previous studies. However, contrary to one study (Macedo, 2017), EE has no significant relationship. It might be due to the nature of the AI technology offerings where people tend to use third-party services, APIs, and libraries without worrying much about the techniques' intricacies for the potential outcomes.

As suggested by Nambisan, Wright, \& Feldman (2019b), Openness plays a significant role for digital entrepreneurship as it reflects the nature of participation, contribution, process and outcome that an actor may be involved with to engage in entrepreneurial activities. Our findings suggest a strong relationship between Openness and AI acceptance intention. Entrepreneurs keen on accepting AI, look for novel ways to streamline entrepreneurial activities and offerings (Kallinikos et al., 2013; Tiwana, 2014; Wareham et al., 2014). This can be accomplished by developing or using digital resources and technological architecture to support digital platforms and technology ecosystems to facilitate collaboration, joint decisionmaking, and governance. Generativity, as observed by Nambisan, Wright, \& Feldman (2019b) determines technology capability to produce unprompted change by involving large unrelated and uncoordinated entities/actors. We notice a positive relationship between generativity and the acceptance intention of AI. The advancements in the AI landscape make its availability on multiple channels using market services. Entrepreneurs can integrate multiple services through the market (open source, collaboration, and outsource) to develop core solutions (Pfau and Rimpp, 2021). As such, the generativity of AI affects AI acceptance intention.

Additionally, we observe Affordance is not directly related to AI acceptance intention. However, as the degree of believing that there is an appropriate AI affordance in terms of digital, organizational, resource, and technical infrastructure to support AI for entrepreneurial activities, entrepreneurs will have a more favorable attitude towards AI (Faraj \& Azad, 2012). 
In turn, entrepreneurs with a positive attitude are motivated to accept digital entrepreneurship. Besides, Inconvenience related to AI has a significant negative relationship with the acceptance intention. Entrepreneurs face inconvenience in integrating AI services to offer core solutions and get affected by its unintended consequences, misuse, algorithmic bias, data, and privacy issues (McKinsey, 2018). As such, entrepreneurs have a long way to conveniently use AI until it becomes more interpretable, capable of handling bias and misuse. Moreover AI should also facilitate seamless integration of services and readiness to deploy robust policies for data and privacy to eliminate Inconvenience. Lastly, the proposed relationship between Uncertainty and AI acceptance intention was not confirmed, but on the contrary, a direct and positive relationship was observed. AI advancements both in generalized and specialized fields provide opportunities to the entrepreneurs. We apprehend that there might not be any conclusive results pertaining to AI automation affecting the market fit adoption due to job and workforce disruption (Akst, 2013).

\subsection{Implications to Theory}

This research explores the motivation behind the intention of entrepreneurs to accept artificial intelligence (AI). We contribute towards the advancement in AI's theoretical progress (Dwivedi et al. 2021; Duan, Edwards \& Dwivedi, 2019), specifically in the domain of entrepreneurship. We complement and extend existing technology adoption/acceptance theories (Kwonsang, \& Ohbyung, 2020; Venkatesh et al. 2012) and digital entrepreneurship theories (Nambisan, 2017; Nambisan \& Baron, 2019a; Nambisan, Wright, \& Feldman, 2019b;

Chalmers, MacKenzie, \& Carter, 2020) by developing a theoretical model, Artificial Intelligence Acceptance and Digital Entrepreneurship (AIADE), explaining the entrepreneur's intention to accept AI. We provide significant evidence and contribution in support of the advancements in the AI-digital entrepreneurship intersection: 
1. Our findings support the suggestion made by Nambisan, Wright, \& Feldman (2019b) that openness, affordance and generativity play an important role in digital entrepreneurship.

2. Openness related to AI has shown a high positive impact on an entrepreneur's intention to accept AI.

3. Affordance has an indirect relationship to AI acceptance intention through Attitude.

4. Generativity has a positive relationship with the entrepreneur's intention to accept AI.

Entrepreneurship literature advocates the importance of Attitude in the adoption of technology.

We establish this fact, and also posit that affordance affects the Attitude, which in turn affects the entrepreneur's intention to accept AI. We also confirm that generativity affects AI acceptance intention. We consider inconvenience and uncertainty that are attributed to the technology acceptance decision (Blut, Wang, \& Schoefer, 2016; McMullen, \& Shepherd, 2006), as this was not considered by previous studies.

This study arouses the significance of entrepreneur's intention to accept AI for digital entrepreneurship and generates scope for further research about its impacts on antecedents of AI-digital entrepreneurship intersection, especially towards acceptance of AI. Moreover, this study provided findings on entrepreneurs' intention to accept AI based on empirical data from 476 respondents. It is expected that the undertaken empirical research based on adequate data samples and suggestive implications will act as a steppingstone in the sparse and infant literature of digital entrepreneurship (Shukla \& Mattar, 2019). Wu \& Chuang (2009) advocate the significance of competitive pressure, which is a part of Porter's five-force model (1980), in deploying any technology. As such, entrepreneurs who receive competitive pressure from competitors using AI tend to accept and deploy the AI technology to gain and retain the competitive advantage (Lai et al., 2018). Davenport (2014) suggests that AI becomes relevant and crucial for enterprises to outperform their competitors by predicting trends and changes in the market and adjusting business strategy, model, and portfolio. We anticipate that 
entrepreneurs' exposure and awareness to AI's generativity, affordance, and openness help them accept AI and enhance digital entrepreneurship.

\subsection{Implications to Practice}

We provide several contributions to the practice in the AI-digital entrepreneurship domain. Pfau and Rimpp (2021) observe four strategic implications of AI applications for entrepreneurs - outsourcing, incremental, profound, and disruptor. Besides, strategic implications have an impact on the business models of the ventures. Our findings confirming openness, affordance, and generativity for digital entrepreneurship will help support such strategic implications. Entrepreneurs keen on offering AI core functions can consider openness, affordance, and generativity aspects of AI to achieve a competitive advantage. Several existing market offerings can be considered to create solutions. Pfau and Rimpp (2021) suggest that application, which has a weak impact on the business model, can be procured from the market and thus, generativity and openness become prominent. Also, affordance becomes critical when AI applications have an impact on business models. An incremental improvement in the offerings will have a moderate impact on the business model. As such, entrepreneurs can weigh affordance, openness, and generativity to decide on developing solutions either in-house or outsource it. Our findings suggest that affordance through attitude affect the intention to accept AI. As such, better AI affordance for entrepreneurial activities will have a more favorable attitude towards AI (Faraj \& Azad, 2012). In turn, entrepreneurs with a positive attitude will be inclined to the acceptance of digital entrepreneurship positively. Accordingly, we suggest that intentional improvement planning is developed by increasing entrepreneurs' positive perceptions of AI affordance and explanation of its generativity and openness, and improving their attitude of using AI for digital entrepreneurship. Besides, performance expectancy, hedonic motivation, and social influence play a vital role in affecting AI acceptance decisions. 
Thus, finding and interacting with people who use AI without much effort and potentially use and offer solutions can have a significant and positive impact on the entrepreneurs' acceptance intentions.

The research findings also have implications for policymakers, marketers, and public agencies in improving AI diffusion and enhancing digital entrepreneurship. Additionally, it will benefit them primarily by exploring and understanding entrepreneur's intention to accept AI. Roger's (2003) argued the importance of (near-)peer evaluation of technology adoption through social influence. Individuals accept new technology based on peer-evaluation rather than solely on scientific research evaluation. When more and more entrepreneurs are willing to accept AI, the peer group is likely to view AI as an efficient and effective mechanism to offer services, solutions, and products. Within the environmental context, the innovation diffusion process is severely impacted by government functioning. Besides, Park and Luo (2001) advocate government influence in formulating and adhering to developing countries' business policies and practices. Government (public) agencies can promote entrepreneurs as early adopters of AI and encourage others to look at them to increase penetration of digital entrepreneurship. For this purpose, Government and public agencies can consider select entrepreneurs who are open to use AI and use their testimonials to get the attention of the large-scale diffusion of AI among entrepreneurs. These active entrepreneurs should be incentivized to promote and share their experiences via social media platforms, public forums, and government events. Such actions help agencies to formulate strategic plans to increase the diffusion of AI. This study also offers a clue to AI marketers. AI marketers can help entrepreneurs accept AI for digital entrepreneurship by providing them with appropriate, continuous, and timely support and services (Chang, 2004). 
Marketers should focus on exporting APIs and services to increase the efficiency and effectiveness of the solutions. Besides, by focusing on entrepreneur's hedonic motivations and performance expectancy of using AI, marketers can offer specific, customize and personalize services and solutions. To increase positive attitude towards acceptance of AI, we suggest that governmental agencies should develop implementation strategies that emphasize the affordance, generativity and openness of AI in digital entrepreneurship ecosystem. Considering the expectation of AI to develop national benefits in the future, several countries have initiated strategic plans for effective digital entrepreneurship. For example, in Italy, a specific national AI agency for digital is established. Such an AI agency aims to facilitate the AI ecosystem's development, foster relationships, and share knowledge among the ecosystem actors (AI Agency Task Force, 2018). India's national strategy for AI embarks its journey by establishing a vibrant AI ecosystem to focus on harnessing AI's power for research, skilling for the AI age, and accelerating AI adoption (NITI Aayog, 2018). Besides, the US has established a national AI initiative office to foster AI research investment and utilize AI computing and data resources to attain AI leadership (Office of Science \& Technology Policy, 2020). We suggest that policymakers who aim to develop an AI ecosystem for digital entrepreneurship should consider the attractiveness of AI ecosystem services, solutions, products, and knowledge sharing for entrepreneurs. Even if an AI service or solution is easy to use but is not attractive for entrepreneurs, they would not be motivated to use it. Besides, Government can offer appropriate incentives to initiate AI-digital entrepreneurship R\&D activities and allocate specific budgets to both human training in upskilling and upgrading legal and institutional frameworks for seamless acceptance of AI (Kitchin, 2014; World Economic Forum, 2012). Such kind of strategy can boost up AI acceptance among entrepreneurs in the private sector. Additionally, open data available to fuel AI will help entrepreneurs appreciate openness in scaling their services and solutions (Kim, Trimi, \& Chung, 2014). 


\subsection{Limitations and recommendations for future research}

This research reveals critical factors explaining intention of entrepreneurs to accept Artificial Intelligence for Digital Entrepreneurship. However, still, the work undertaken is not devoid of all limitations. The responses that were analysed to validate the theorized model may not be adequate to be generalized the findings. Further research in this direction can be considered to cover the large sample size to address such an issue. Besides, the responses were received through online channel and further research work can focus on adopting mixed method analysis. It will be interesting to explore both the qualitative and quantitative analysis to further strengthen the theorized model. Further qualitative studies can be conducted to obtain an in-depth understanding of factors such as culture, infrastructure, change, leadership and policy (Weerakkody et al., 2007; 2009). In the proposed model, the variance is explained through Artificial Intelligence Acceptance Intention (49.4\%) and Attitude (46.6\%). However, attempts may be made to consider other boundary conditions, such as trust, risks and so on, to examine whether such inclusion can affect the variance and explanation of the model.

\section{Conclusion}

The undertaken study has been able to identify factors affecting the intention of entrepreneurs to accept artificial intelligence for digital entrepreneurship. The theorized artificial intelligence acceptance and digital entrepreneurship model has captured the model's variance explanation through artificial intelligence acceptance intention (AIAI) and attitude (AT). This study has shown that performance expectancy $(\mathrm{PE})$, openness $(\mathrm{OP})$, social influence (SI), hedonic motivations (HM), and generativity (GE) have a positive impact on entrepreneurs' acceptance intention. Additionally, affordance (AF) has no direct relationship with AI acceptance intention, but it affects AI acceptance intention through AT. Inconvenience (IN) has a significant negative relationship with the intention to accept $\mathrm{AI}$, while uncertainty (UN) was found to be positively affecting the AI acceptance intention. Effort expectancy (EE) did not confirm any significant relationship. The theorized model complement and extend existing technology adoption/acceptance theories 
(Kwonsang, and Ohbyung, 2020; Venkatesh et al. 2012) and digital entrepreneurship theories (Nambisan, 2017; Nambisan \& Baron, 2019a; Nambisan, Wright, \& Feldman, 2019b; Chalmers, MacKenzie, \& Carter, 2020). The study findings have contributed to several implications for both theory and practice. Government has to relook potential strategies to develop an AI ecosystem to operationalize large-scale AI diffusion for digital entrepreneurship. As such, policymakers have to provide a flexible, attractive, open, and collaborative environment. Entrepreneurs can alleviate AI acceptance by understanding its generativity, affordance, and openness. Marketers can consider entrepreneur's hedonic motivation and performance expectancy to offer personalized services and solutions. It is expected that the theorized model will help advance AI's theoretical progress (Dwivedi et al., 2021; Duan, Edwards \& Dwivedi, 2019), specifically in the domain of entrepreneurship.

\section{References}

Agrawal, A., Gans, J., \& Goldfarb, A. (2018), "Prediction machines: the simple economics of artificial intelligence", Harvard Business Press.

AI Agency Task Force. (2018), “Artificial Intelligence Ecosystem”, Retrieved from https://ia.italia.it/en/ai-in-italy/

Ajzen, I. (1991)", The theory of planned behaviour", Organizational Behaviour \& Human Decision. Process, Vol.50, pp 179-211.

Akst, D. (2013), "What can we learn from past anxiety over automation? The Wilson Quarterly”. Retrieved from https:// wilsonquarterly.com/quarterly/summer-2014-wherehave-all-the-jobs-gone/theres-much-learn-from-past-anxiety- over-automation/

Anderson, C., (2014), “Makers: The New Industrial Revolution”, Crown Business.

Armstrong, J. S., \& Overton, T. S. (1977), "Estimating nonresponse bias in mail surveys. Journal of Marketing Research", Vol.14, pp. 396-402.

Bag, S., Pretorius, J. H. C., Gupta, S., \& Dwivedi, Y. K. (2021), "Role of institutional pressures and resources in the adoption of big data analytics powered artificial intelligence, 
sustainable manufacturing practices and circular economy capabilities", Technological Forecasting and Social Change, Vol. 163, pp. 120420.

Balakrishnan, J., \& Dwivedi, Y. K. (2021), "Role of cognitive absorption in building user trust and experience”, Psychology \& Marketing, Vol. 38 No. 4, pp. 643-668.

Bandura, A. (1978), "Reflections on self-efficacy", Advances in Behaviour Research and Therapy, Vol.1, 237-269

Bandura, A. (1986), "Social Foundations of Thought and Action: A Social Cognitive Theory", Prentice Hall, Engle wood Cliffs, N J, 1986

Bharadwaj A, Sawy A. El. O., Pavlou, P. A., Venkatraman, N. (2013), "Digital business strategy: towards a next generation of insights”, MIS Quarterly, Vol. 37 No. 2, pp. 471-482

Bilton, N. (2015). Siri, tell me a joke. No, a funny one. The New York Times. Retrieved from https://www.nytimes.com/2015/ 08/13/fashion/siri-tell-me-a-joke-no-a-funny-one.html

Blut, M., Wang, C., \& Schoefer, K. (2016), "Factors influencing the acceptance of self-service technologies: A meta-analysis”, Journal of Service Research, Vol.19 No. 4,pp. 396-416.

Borges, A. F., Laurindo, F. J., Spínola, M. M., Gonçalves, R. F., \& Mattos, C. A. (2021), “The strategic use of artificial intelligence in the digital era: Systematic literature review and future research directions”, International Journal of Information Management, Vol. 57, pp. 102225.

Chalmers, D., MacKenzie, N, G., and Carter, S. (2020), "Artificial Intelligence and Entrepreneurship: Implications for Venture Creation in the Fourth Industrial Revolution”, Entrepreneurship Theory and Practice

Chang, S.I. (2004), "ERP life cycle implementation, management and support: Implications for practice and research", Proceedings of the 37th Annual Hawaii International Conference on System Sciences (HICSS-37). 
Chidlow, A., Ghauri, P., Yeniyurt, S. and Cavusgil, S.T. (2015), "Establishing rigor in mail survey procedures in international business research", Journal of World Business, Vol. 50 No. 1, pp. 26-36.

Cockburn, I. M., Henderson, R., \& Stern, S. (2018), “The impact of artificial intelligence on innovation", National Bureau of Economic Research.

Collier, J. E., \& Kimes, S. E. (2013), “Only if it is convenient: Understanding how convenience influences self-service tech- nology evaluation”, Journal of Service Research, Vol.16 No. 1,pp. 39-51.

Compeau, D. R., and Higgins, C. A. (1995), "Computer self-efficacy: development of a measure and initial test”, MIS Quarterly, Vol. 19,pp. 189-211.

Couper, M.P. (2017), "New developments in survey data collection", Annual Review of Sociology, Vol. 43, pp. 121-145.

Davenport, T. (2014), "Big data at work: Dispelling the myths, uncovering the opportunities", Cambridge, MA: Harvard University Press.

Davis, F. D. (1989), "Perceived usefulness, perceived ease of use, and user acceptance of information technology”, MIS Quarterly, Vol.13, pp.319

Davis, F. D., Bogozzi, R. P., \& Warshaw, P. R. (1989), "User acceptance of computer technology: A comparison of two theoretical models". Management Science, Vol. 35, 9821003.

Deb, M. and David, E.L. (2014), “An empirical examination of customers' adoption of mbanking in India”, Journal of Marketing Intelligence \& Planning, Vol. 32 No. 4, pp. 475494.

Deci, E. L., \& Ryan, R. M. (1985), "Intrinsic motivation and self-determination in human behavior", New York: Plenum. 
Deci, E. L., Koestner,R., \& Ryan, R. M. (1999), “A meta-analytic review of experiments examining the effects of extrinsic rewards on intrinsic motivation", Psychological Bulletin, Vol. 125,627-668.

Demlehner, Q., Schoemer, D., \& Laumer, S. (2021), "How can artificial intelligence enhance car manufacturing? A Delphi study-based identification and assessment of general use cases”, International Journal of Information Management, Vol. 58, pp. 102317.

Donald, M. (1991), “Origins of the Modern Mind: Three Stages in the Evolution of Culture and Cognition". Harvard University Press, Cambridge, MA.

Donald, M., (1991), “Origins of the Modern Mind: Three Stages in the Evolution of Culture and Cognition", Harvard University Press, Cambridge, MA.

Duan, Y., Edwards, J.S., Dwivedi, Y.K. (2019), “Artificial intelligence for decision making in the era of Big Data - evolution, challenges and research agenda." International Journal of Information Management, Vol. 48, pp.63-71

Dubey, R., Bryde, D. J., Foropon, C., Tiwari, M., Dwivedi, Y., \& Schiffling, S. (2021), “An investigation of information alignment and collaboration as complements to supply chain agility in humanitarian supply chain”, International Journal of Production Research, Vol. 59 No. 5, pp. 1586-1605.

Dwivedi, Y. K., Hughes, L., Ismagilova, E., Aarts, G., Coombs, C., Crick, T., ... \& Williams, M. D. (2021), “Artificial Intelligence (AI): Multidisciplinary perspectives on emerging challenges, opportunities, and agenda for research, practice and policy" International Journal of Information Management, Vol. 57, pp. 101994.

Dwivedi, Y. K., Ismagilova, E., Hughes, D. L., Carlson, J., Filieri, R., Jacobson, J., ... \& Wang, Y. (2020), "Setting the future of digital and social media marketing research: Perspectives and research propositions”, International Journal of Information Management, pp. 102168, doi: 10.1016/j.ijinfomgt.2020.102168. 
Dwivedi, Y. K., Rana, N. P., Jeyaraj, A., Clement, M., \& Williams, M. D. (2019), "Reexamining the unified theory of acceptance and use of technology (UTAUT): Towards a revised theoretical model”, Information Systems Frontiers, Vol. 21 No. 3, pp. 719-734.

Dwivedi, Y. K., Rana, N. P., Janssen, M., Lal, B., Williams, M. D., \& Clement, M. (2017), "An empirical validation of a unified model of electronic government adoption (UMEGA)", Government Information Quarterly, Vol. 34 No. 2, pp. 211-230.

Dwivedi, Y. K., Khan, N., \& Papazafeiropoulou, A. (2007), “Consumer adoption and usage of broadband in Bangladesh”, Electronic Government, an International Journal, Vol. 4 No. 3, pp. 299-313.

Dwivedi, Y. K., \& Weerakkody, V. (2007), "Examining the factors affecting the adoption of broadband in the Kingdom of Saudi Arabia", Electronic Government, an International Journal, Vol. 4 No. 1, pp. 43-58.

Esbia, R H. (2009), "Digital artifacts as quasi-objects: Qualification, mediation, and materiality”, Journal of the American Society for Information Science and Technology, Vol. 60. No. 12.

European Commission. (2017), "Work Programme", Retrieved https://ec.europa.eu/commission/work-programme-2017_en

Evans, J.R. and Mathur, A. (2005), “The value of online surveys”, Internet Research, Vol. 15, No. 2, p. 197.

Evans, J.R. and Mathur, A. (2018), "The value of online surveys: a look back and a look ahead", Internet Research, Vol. 28 No. 4, pp. 854-887.

Faraj, S. and B. Azad (2012), "The materiality of technology: An affordance perspective", In: Nardi, L. B. \& J., K. (eds.) Materiality and organizing: Social interaction in a technological world. NY City: Oxford University Press. 
Fornell, C., \& Larcker, D. F. (1981), "Evaluating structural equation models with unobservable variables and measurement error", Journal of Marketing Research, Vol.18, pp.39-50.

Fulantelli, G., \& Allegra, M. (2003), "Small company attitude towards ICT based solutions : some key-elements to improve it technologies for cooperation : the supply chain partnership project”, Educational Technology \& Society, Vol.6 No.1, 45-49.

Ghosh. S \& Bhowmick,B. (2014), "Technological Uncertainty: Exploring Factors in Indian Start-Ups", Proceedings of IEEE 2014 Global Humanitarian Technology Conference

Gibson, J. J (1979), "The theory of affordances. The ecological approach to visual perception", Houghton Mifflin, Hopewell: pp.127-143

Giones, F. and Brem, A. (2017), "Digital technology entrepreneurship: a definition and research agenda", Technology Innovation Management Review, Vol. 7 No. 5, pp. 44-51.

Goswami, A. and Dutta, D. (2016), “E-Commerce adoption by women entrepreneurs in India: an application of the UTAUT model”, Business and Economic Research, Vol. 6 No. 2, pp. $440-454$.

Grover, P., Kar, A. K., \& Dwivedi, Y. K. (2020), "Understanding artificial intelligence adoption in operations management: insights from the review of academic literature and social media discussions", Annals of Operations Research, 1-37, doi: https://doi.org/10.1007/s10479-020-03683-9

Gursoy, D., Chi, O. H., Lu, L., \& Nunkoo, R. (2019), “Consumers acceptance of artificially intelligent (AI) device use in service delivery", International Journal of Information Management, Vol. 49, pp.157-169.

Hair, J.F., Risher, J., Sarstedt, M. and Ringle, C.M. (2018), "When to use and how to report the results of PLS-SEM”, European Business Review, Vol. 31 No. 1, pp. 2-24.

Halaweh, M., (2013), "Emerging Technology: What is it?" Journal of Technology Management and Innovation, Vol.8 No.3 
Hall, J., Matos, S., Silvestre B., and Martin, M., (2011),“Managing technological and social uncertainties of innovation: The evolution of Brazilian energy and agriculture" Technological Forecasting \& Social Change, Vol.78, pp. 1147-1157

Harzing, A.W., Brown, M., Köster, K. and Zhao, S. (2012), "Response style differences in cross-national research: dispositional and situational determinants", Management International Review, Vol. 52 No. 3, pp. 341-363.

Henseler, J., Hubona, G., \& Ray, P. A. (2016), “Using PLS path modeling in new technology research: Updated guidelines", Industrial Management \& Data Systems, Vol.116 No.1, pp. $2-20$.

Hill, J., Ford, W. R., \& Farreras, I. G. (2015), "Real conversations with artificial intelligence: A comparison between human- human online conversations and human-chatbot conversations", Computers in Human Behavior, 4 Vol.9, 245-250.

Hsieh, Y.-J. and Wu, Y. (2018), "Entrepreneurship through the platform strategythe digital era: insights and research opportunities", Computers in Human Behavior, pp. 1-9.

Hu, M., Hung, S. C., Gao, J., (2011), "Emerging technologies in emerging markets: Introduction to the special section" Technological Forecasting \& Social Change, Vol.78, pp. $1101-1103$

Huang, H. M., \& Liaw, S. S. (2005), “Exploring users' attitudes and intentions toward the web as a survey tool", Computers in Human Behavior, Vol.21 No.5, pp. 729-743.

Hull, C.E., Hung, Y.-T.C., Hair, N., Perotti, V. and DeMartino, R. (2007), “Taking advantage of digital opportunities: a typology of digital entrepreneurship", International Journal of Networking and Virtual Organizations, Vol. 4 No. 3, pp. 290-303.

Ilieva, J., Baron, S., \& Healey, N. M. (2002), “Online surveys in marketing research: pros and cons. International Journal of Market Research”, Vol. 44 No. 3, pp. 361-376. 
Kallinikos, J., Aaltonen, A., Marton, A., (2013), “The ambivalent ontology of digital artifacts", MIS Quarterly, Vol. 41 No. 1, pp.239-253

Kim, G.-H., Trimi, S., and Chung, J.H. (2014), "Big-data applications in the government sector", Communications of the ACM, Vol. 57 No. 3, pp.78-85.

Kim, M.K., and Park, J.H. (2017), "Identifying and prioritizing critical factors for promoting the implementation and usage of big data in healthcare. Information Development", Vol. 33 No.3, pp. 257-269.

Kitchin, R. (2014), “The data revolution: Big data, open data, data infrastructures and their consequences", London: Sage.

Kraus, S., Palmer, C., Kailer, N., Kallinger, L. F., Spitzer, J. (2018), "Digital entrepreneurship: A research agenda on new business models for the twenty-first century", International Journal of Entrepreneurial Behavior \& Research

Kuester, S., Konya-Baumbach, E., Schuhmacher, M.C.(2018), "Get the show on the road: Goto-market strategies for E-innovations of start-ups”, Journal of Business Research, Vol. 83C, pp. $65-81$

Kwonsang, S, and Ohbyung, K.(2020), "Technology acceptance theories and factors influencing artificial Intelligence-based intelligent products”, Telematics and Informatics, Vol. 47

Lai, Y., Sun, H., and Ren, J. (2018), "Understanding the determinants of big data analytics (bda) adoption in logistics and supply chain management: An empirical investigation", International Journal of Logistics Management, Vol. 29 No. 2, pp. 676-703.

Le Dinh, T., Vu, M.C. and Ayayi, A. (2018), “Towards a living lab for promoting the digital entrepreneurship process”, International Journal of Entrepreneurship, Vol. 22 No. 1, pp. 117. 
Lee, J., Suh, T., Roy, D., \& Baucus, M. (2019), “Emerging Technology and Business Model Innovation: The Case of Artificial Intelligence", Journal of Open Innovation: Technology, Market, and Complexity, Vol.5 No.3,pp. 44.

Leonard-Barton, D. and Deschamps, I. (1988), "Managerial influence in the implementation of new technology", Management Science, Vol. 34, pp. 1252-1265.

Liebregts, W., Darnihamedani, P., Postma, E., \& Atzmueller, M. (2019), “The promise of social signal processing for research on decision-making in entrepreneurial contexts", Small Business Economics, Vol. 39 No. 1.

Loebbecke, C., \& Picot, A. (2015), "Reflections on societal and business model transformation arising from digitization and big data analytics: A research agenda”, The Journal of Strategic Information Systems, Vol.24 No.3,pp. 149-157.

Lyytinen, K., Sørensen, C., Tilson, D., (2017), “Generativity in digital infrastructures: a research note", The Routledge Companion to Management Information Systems. Routledge, pp. 253-275.

Lyytinen, K., Yoo, Y., Boland Jr., R.J., (2016), “Digital product innovation within four classes of innovation networks", Information Systems Journal, Vol. 26 No. 1,pp. 47-75.

Macedo, I.M. (2017), "Predicting the acceptance and use of information and communication technology by older adults: an empirical examination of the revised UTAUT2", Computers in Human Behavior, Vol. 75, pp. 935-948.

Makridakis, S. (2017), “The forthcoming Artificial Intelligence (AI) revolution: Its impact on society and firms", Futures, Vol.90, pp.46-60.

McMullen, J. S., \& Shepherd, D. A. (2006), “Entrepreneurial action and the role of uncertainty in the theory of the entrepreneur", Academy of Management Review, Vol.31 No.1, pp.132152. 
Mellahi, K. and Harris, L.C. (2016), "Response rates in business and management research: an overview of current practice and suggestions for future directions", British Journal of Management, Vol. 27 No. 2, pp. 426-437.

Moghavvemi, S., Salleh, N.A.M. and Standing, C. (2016), "Entrepreneurs adoption of information system innovation: the impact of individual perception and exogenous factors on entrepreneurs behavior", Internet Research, Vol. 26 No. 5, pp. 1181-1208.

Nägle, S. and Schmidt, L. (2012), "Computer acceptance of older adults”, Work, Vol. 41 No. 1, pp. 3541-3548.

Nambisan, S. (2017), "Digital entrepreneurship: Toward a digital technology perspective of entrepreneurship", Entrepreneurship Theory and Practice, Vol.41 No. 6, pp.1029-1055.

Nambisan, S., \& Baron, R. A. (2019a), “On the costs of digital entrepreneurship: Role conflict, stress, and venture performance in digital platform-based ecosystems", Journal of Business Research, Vol.48.

Nambisan, S., Wright, M., \& Feldman, M.(2019b), “The digital transformation of innovation and entrepreneurship: Progress, challenges and key themes, Research Policy, Vol. 48

NITI Aayog. (2018), "National Strategy for Artificial Intelligence", Retrieved from https://niti.gov.in/writereaddata/files/document_publication/NationalStrategy-for-AIDiscussion-Paper.pdf

Obschonka, M., \& Audretsch, D. B. (2019), "Artificial intelligence and big data in entrepreneurship: A new era has begun", Small Business Economics, Vol. 19, No. 1

Office of Science and Technology Policy. (2020), “American Artificial Intelligence Initiative: Year One Annual Report", Retrieved from https://www.nitrd.gov

Overby, J, W., Lee E. (2006), “The effects of utilitarian and hedonic online shopping value on consumer preference and intentions”, Journal of Business Research, Vol. 59, pp.1160-1166 
Park, S. H., \& Luo, Y. (2001), "Guanxi and organizational dynamics: Organizational networking in chinese firms”, Strategic Management Journal, Vol. 22 No.5, pp. 455-477.

Pfau W., Rimpp P. (2021), “AI-Enhanced Business Models for Digital Entrepreneurship”, In: Soltanifar M., Hughes M., Göcke L. (eds) Digital Entrepreneurship. Future of Business and Finance. Springer, Cham.

Pillai, R., Sivathanu, B., \& Dwivedi, Y. K. (2020). "Shopping intention at AI-powered automated retail stores (AIPARS)", Journal of Retailing and Consumer Services, Vol. 57, pp. 102207.

Pillai, R., Sivathanu, B., Mariani, M., Rana, N. P., Yang, B., \& Dwivedi, Y. K. (2021), "Adoption of AI-empowered industrial robots in auto component manufacturing companies", Production Planning \& Control, pp. 1-17, doi: $10.1080 / 09537287.2021 .1882689$

Podsakoff, P. M., \& Organ, D. W. (1986), "Self-reports in organizational research: Problems and prospects. Journal of Management”, Vol.12 No.4,pp. 531-544.

Pol, E., \& Reveley, J. (2017), "Robot induced technological unemployment: Towards a youthfocused coping strategy", Psychosociological Issues in Human Resource Management, Vol.5 No.2, pp.169-186.

Porter, M. E. (1980), “Competitive strategy: Techniques for analyzing industries and competitors", New York: Free Press.

Ringle, C. M., Wende, S., \& Becker, J.-M. (2015), "SmartPLS 3. Boenningstedt: SmartPLS GmbH”, Retrieved from https://www. smartpls.com

Rogers, E. M. (2003), "Diffusion of Innovations", 5th Edn. New York, NY: Simon and Schuster.

Rothwell, R., Freeman, C., Horsley, A., Jervis, V.T.P., Robertson, A.B., Townsend, J. (1974), “SAPPHO updated project Sappho phase II”, Research Policy, Vol. 3, 258-291 
Selm, M. V. (2006), “Conducting Online Surveys”, Quality \& Quantity, Vol.40, pp:435-456

Shareef, M. A., Kumar, V., Dwivedi, Y. K., Kumar, U., Akram, M. S., \& Raman, R. (2021), “A new health care system enabled by machine intelligence: Elderly people's trust or losing self control", Technological Forecasting and Social Change, Vol. 162, pp. 120334

Shane, S. (2000), "Prior knowledge and the discovery of entrepreneurial opportunities" Organization science, Vol.11 No. 4, pp.448-469.

Sheppard, B. H., HartwickJ, and Warshaw, P. R. (1988), “The Theory of Reasoned Action: A Meta- Analysis of Past Research with Recommendations for Modification as Future Research”, Journal of Consumer Research, Vol. 15 No.3, pp. 325-343.

Shukla, M., \& Mattar, L. (2019), "Next generation smart sustainable auditing systems using big data analytics: Understanding the interaction of critical barriers:, Computers \& Industrial Engineering, Vol. 128, pp. 1015-1026.

Skilton, M., Hovsepian, F. (2018), “The 4th Industrial Revolution. Responding to the Impact of Artificial Intelligence on Business”, Cham: Springer International Publishing.

Song, X. M., and Montoya-Weiss, M., (2001), "The effect of perceived technological uncertainty on Japanese new product development”. Academy of Management

Streukens, S., \& Leroi-Werelds, S. (2016), "Bootstrapping and PLS-SEM: A step-by-step guide to get more out of your boot- strap results”, European Management Journal, Vol.34 No.6, pp.618-632.

Sussan, F. and Acs, Z. (2017), "The digital entrepreneurial ecosystem”, Small Business Economics, Vol. 49 No. 1, pp. 55-73

Tamilmani, K., Rana, N. P., Prakasam, N., \& Dwivedi, Y. K. (2019), “The battle of Brain vs. Heart: A literature review and meta-analysis of "hedonic motivation" use in UTAUT2”, International Journal of Information Management, Vol. 46, pp. 222-235. 
Taylor, S., and Todd, P. A. (1995), "Understanding Information Technology Usage: A Test of Competing Models”, Information Systems Research, Vol. 6, No.4,pp. 144-176

Tenenhaus, M., Vinzi, V. E., Chatelin, Y. M., \& Lauro, C. (2005), "PLS path modeling. Computational Statistics \& Data Analysis", Vol.48 No.1, 159-205

The World Bank. (2019). World Development Report 2019: The Changing Nature of Work. World Bank Groupo.

Tilson, D., Lyytinen, K., Sørensen, C., (2010), “Digital infrastructures: the missing IS research agenda”, Information System Researchg, Vol.21 No.4, pp.748-759.

Tiwana, A., (2014), “Platform Ecosystems: Aligning Architecture, Governance, and Strategy", Morgan Kaufmann.

Tornatzky, L. and Fleischer, M. (1990), “The process of technology innovation”, Lexington, MA, Lexington Books.

Townsend, D. M., \& Hunt, R. A. (2019), "Entrepreneurial action, creativity, \& judgment in the age of artificial intelligence” Journal of Business Venturing Insights, Vol.11

Turner, M., Fauconnier, G. (1997), “A mechanism of creativity”, Poet Today, Vol. 20, No.4, pp. 397-418.

Van der Heijden, H. (2003), "Factors Influencing the Usage of Websites: The Case of a Generic Portal in the Netherlands," Information and Management, Vol. 40 No.6, pp. 541-549.

Venkatesh, V., Morris, M. G., Davis, G. B., \& Davis, F. D. (2003), "User acceptance of information technology: Toward a unified view”, MIS Quarterly, Vol.27 No.3, pp. 425478.

Venkatesh, V., Thong, J. Y. L., \& Xu, X. (2012), “Consumer acceptance and use of information technology: Extending the unified theory of acceptance and use of technology", MIS Quarterly, Vol.36, No.1, 157-178. 
von Briel, F., Davidsson, P., Recker, J., (2018), "Digital technologies as external enablers of new venture creation in the IT hardware sector", Entrepreneurship \& Theory Practice. Vol.42 No. 1,pp. 47-69.

Vuong, B. N., \& Sid, S. (2020), “The impact of human resource management practices on employee engagement and moderating role of gender and marital status: An evidence from the Vietnamese banking industry", Management Science Letters

Wareham, J., Fox, P.B., Cano Giner, J.L., (2014), “Technology ecosystem governance”, Organization Science, Vol.25 No.4, pp.1195-1215.

Weerakkody, V., Dwivedi, Y. K., Brooks, L., Williams, M. D., \& Mwange, A. (2007), "Egovernment implementation in Zambia: contributing factors", Electronic government, an international journal, Vol. 4 No. 4, pp. 484-508.

Weerakkody, V., Dwivedi, Y. K., \& Kurunananda, A. (2009), “Implementing e-government in Sri Lanka: Lessons from the UK”, Information Technology for Development, Vol. 15, No 3, pp. 171-192.

Willaby, H.W., Costa, D.S.J., Burns, B.D., MacCann, C. and Roberts, R.D. (2015), “Testing complex models with small sample sizes: a historical overview and empirical demonstration of what partial least squares (PLS) can offer differential psychology", Personality and Individual Differences, Vol. 84, pp. 73-78.

Woods, H. S. (2018), “Asking more of Siri and Alexa: Feminine persona in service of surveillance capitalism. Critical Studies in Media Communication”, Vol.35 No.4, pp.334349.

World Economic Forum (2012). "Big data, big impact: New possibilities for international development", 
Wu, L., \& Chuang, C.-H. (2009). Analyzing contextual antecedents for the stage-based diffusion of electronic supply chain management. Electronic Commerce Research and Applications, 8(6), 302-314.

Xavier, T., Vieira, F., \& Rodrigues, C. (2009), “Entrepreneurial Attitudes and Entrepreneurship 's Potential", East Timor, 677-687.

Yoo, Y., Boland Jr., R.J., Lyytinen, K., Majchrzak, A., (2012), “Organizing for innovation in the digitized world", Organization Science, Vol. 23 No.5,pp. 1398-1408.

Zhang, D., Pee, L. G., \& Cui, L. (2021), “Artificial intelligence in E-commerce fulfillment: A case study of resource orchestration at Alibaba's Smart Warehouse", International Journal of Information Management, Vol. 57, pp. 102304.

Zittrain, J., (2006), “The generative Internet”, Harvard Law Review, Vol. 119 No.7, pp.19752040.

Zittrain, J., (2008), “The Future of the Internet and How to Stop It”, Yale University Press, New Haven, CT. 


\section{Table}

Table 1 Antecedents for the intention of the entrepreneur's to accept artificial intelligence

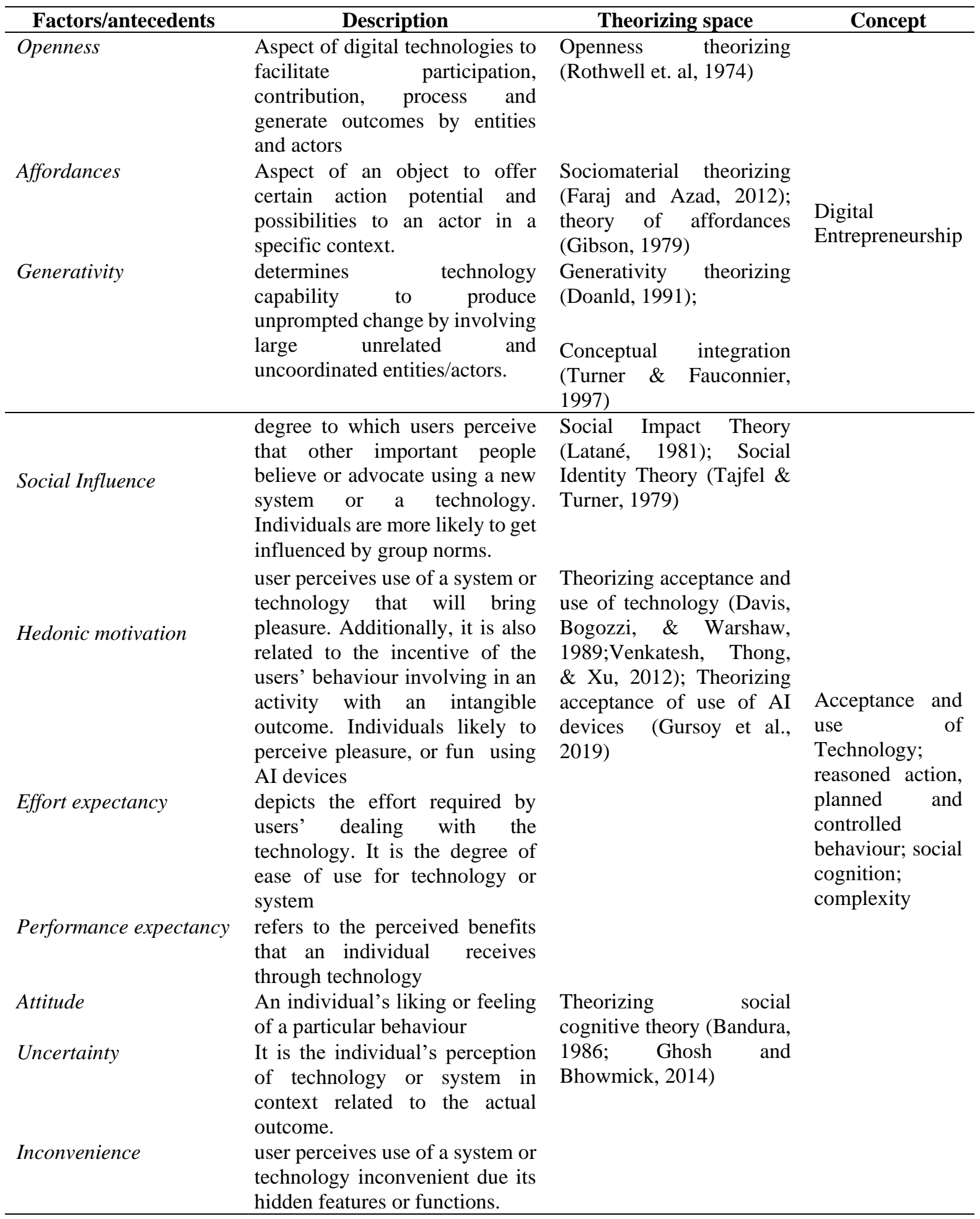


Table 2 Source of constructs

\begin{tabular}{ll}
\hline Construct & Source \\
\hline Performance Expectancy (PE) & Venkatesh et al. (2012) \\
Effort Expectancy (EE) & Venkatesh et al. (2012) \\
Social Influence (SI) & Venkatesh et al. (2012) \\
Hedonic Motivation (HM) & Venkatesh et al. (2012) \\
Attitude (AT) & Bandura (1986); Dabholkar and Bagozzi (2002) \\
Inconvenience (IN) & Hill et al. (2015); Robertson et al. (2016) \\
Uncertainty (UN) & Ghosh and Bhowmick, (2014) \\
Openness (OP) & Rothwell et. al, (1974); Nambisan, (2017); Nambisan \& Baron, \\
& (2019a); Chalmers, MacKenzie, \& Carter, (2020); Nambisan, Wright, \\
& \& Feldman, (2019b) \\
Affordance (AF) & Faraj and Azad, (2012); Gibson, (1979); Nambisan, (2017); Nambisan \\
& \& Baron, (2019a); Chalmers, MacKenzie, \& Carter, (2020); \\
& Nambisan, Wright, \& Feldman, (2019b) \\
Generativity (GE) & Doanld, (1991); Turner \& Fauconnier, (1997); Nambisan, (2017); \\
& Nambisan \& Baron, (2019); Chalmers, MacKenzie, \& Carter, (2020); \\
AI acceptance intention (AIAI) & Nambisan, Wright, \& Feldman, (2019b) \\
\hline
\end{tabular}


Table 3 Demographic characteristics $(n=476)$

\begin{tabular}{|c|c|c|c|c|c|}
\hline \multirow{2}{*}{$\begin{array}{l}\text { Measure } \\
\text { Gender }\end{array}$} & \multicolumn{2}{|l|}{ Item } & Frequency & \multicolumn{2}{|l|}{ Percentage } \\
\hline & \multicolumn{2}{|l|}{ Male } & 356 & \multicolumn{2}{|l|}{74.78} \\
\hline & \multicolumn{2}{|l|}{ Female } & 120 & \multicolumn{2}{|l|}{25.21} \\
\hline \multirow[t]{5}{*}{ Age } & \multicolumn{2}{|l|}{$18 \sim 24$} & 39 & \multicolumn{2}{|l|}{8.19} \\
\hline & \multicolumn{2}{|l|}{$25 \sim 30$} & 95 & \multicolumn{2}{|l|}{19.95} \\
\hline & \multicolumn{2}{|l|}{$31 \sim 35$} & 132 & \multicolumn{2}{|l|}{27.73} \\
\hline & \multicolumn{2}{|l|}{$36 \sim 40$} & 121 & \multicolumn{2}{|l|}{25.42} \\
\hline & \multicolumn{2}{|l|}{ Above 40} & 89 & \multicolumn{2}{|l|}{18.69} \\
\hline \multirow[t]{5}{*}{ Educational Background } & \multicolumn{2}{|c|}{ Junior High School graduate } & 0 & \multicolumn{2}{|l|}{0} \\
\hline & \multicolumn{2}{|c|}{ Senior High School graduate } & 17 & \multicolumn{2}{|l|}{3.57} \\
\hline & \multicolumn{2}{|c|}{ Bachelor's Degree } & 311 & \multicolumn{2}{|l|}{65.33} \\
\hline & \multicolumn{2}{|c|}{ Master's Degree } & 119 & \multicolumn{2}{|l|}{25} \\
\hline & \multicolumn{2}{|c|}{ Doctorate Degree } & 29 & \multicolumn{2}{|l|}{6.09} \\
\hline \multirow[t]{2}{*}{ Marriage Status } & \multirow{2}{*}{\multicolumn{2}{|c|}{$\begin{array}{l}\text { Single } \\
\text { Married }\end{array}$}} & 185 & \multicolumn{2}{|l|}{38.86} \\
\hline & & & 291 & \multicolumn{2}{|l|}{61.13} \\
\hline \multicolumn{6}{|c|}{ Respondents Country } \\
\hline Country & Frequency & Percentage & Country & Frequency & Percentage \\
\hline United States of America & 73 & 15.34 & Germany & 35 & 7.35 \\
\hline China & 64 & 13.45 & India & 33 & 6.93 \\
\hline United Kingdom & 55 & 11.55 & Australia & 28 & 5.88 \\
\hline Italy & 45 & 9.45 & Spain & 27 & 5.67 \\
\hline Russia & 40 & 8.40 & Netherlands & 21 & 4.41 \\
\hline France & 36 & 7.56 & Canada & 19 & 3.99 \\
\hline
\end{tabular}


Table 4. Measurement model assessment

\begin{tabular}{|c|c|c|c|c|c|}
\hline Construct & Loading & Cronbach's alpha & rho_A & Composite reliability & AVE \\
\hline \multicolumn{6}{|l|}{ Performance Expectancy } \\
\hline PE1 & 0.78 & 0.79 & 0.80 & 0.86 & 0.62 \\
\hline PE2 & 0.76 & & & & \\
\hline PE3 & 0.78 & & & & \\
\hline PE4 & 0.81 & & & & \\
\hline Effort Expectancy & & 0.80 & 0.84 & 0.88 & 0.71 \\
\hline EE1 & 0.87 & & & & \\
\hline EE2 & 0.86 & & & & \\
\hline EE3 & 0.79 & & & & \\
\hline Social Influence & & 0.81 & 0.82 & 0.89 & 0.73 \\
\hline SI1 & 0.85 & & & & \\
\hline SI2 & 0.84 & & & & \\
\hline SI3 & 0.86 & & & & \\
\hline Hedonic Motivation & & 0.89 & 0.89 & 0.93 & 0.81 \\
\hline HM1 & 0.91 & & & & \\
\hline HM2 & 0.90 & & & & \\
\hline HM3 & 0.89 & & & & \\
\hline Inconvenience & & 0.71 & 0.71 & 0.83 & 0.63 \\
\hline IN1 & 0.83 & & & & \\
\hline IN3 & 0.75 & & & & \\
\hline IN4 & 0.79 & & & & \\
\hline Uncertainty & & 0.87 & 0.89 & 0.92 & 0.79 \\
\hline UN1 & 0.91 & & & & \\
\hline UN2 & 0.86 & & & & \\
\hline UN3 & 0.89 & & & & \\
\hline Openness & & 0.92 & 0.93 & 0.94 & 0.86 \\
\hline OP1 & 0.90 & & & & \\
\hline OP2 & 0.94 & & & & \\
\hline OP3 & 0.93 & & & & \\
\hline Affordance & & 0.80 & 0.80 & 0.88 & 0.72 \\
\hline AF1 & 0.82 & & & & \\
\hline $\mathrm{AF} 2$ & 0.85 & & & & \\
\hline $\mathrm{AF} 3$ & 0.86 & & & & \\
\hline Attitude & & 0.87 & 0.87 & 0.91 & 0.72 \\
\hline AT1 & 0.86 & & & & \\
\hline AT2 & 0.87 & & & & \\
\hline AT3 & 0.83 & & & & \\
\hline AT4 & 0.83 & & & & \\
\hline Generativity & & 0.84 & 0.85 & 0.89 & 0.68 \\
\hline GE1 & 0.84 & & & & \\
\hline GE2 & 0.82 & & & & \\
\hline GE3 & 0.82 & & & & \\
\hline GE4 & 0.81 & & & & \\
\hline Intelligence & & 0.90 & 0.90 & 0.93 & 0.77 \\
\hline \multicolumn{6}{|l|}{ Acceptance Intention } \\
\hline AIAI1 & 0.90 & & & & \\
\hline AIAI2 & 0.87 & & & & \\
\hline AIAI3 & 0.89 & & & & \\
\hline AIAI4 & 0.85 & & & & \\
\hline
\end{tabular}


Table 5. Discriminant validity results

\begin{tabular}{|c|c|c|c|c|c|c|c|c|c|c|c|}
\hline Construct & GE & UN & AIAI & $\mathrm{EE}$ & $\mathrm{OP}$ & HM & $\mathrm{AF}$ & $\mathrm{PE}$ & AT & SI & IN \\
\hline \multicolumn{12}{|c|}{ Fornell-Larcker } \\
\hline GE & 0.826 & & & & & & & & & & \\
\hline UN & 0.214 & 0.890 & & & & & & & & & \\
\hline AIAI & 0.217 & 0.175 & 0.880 & & & & & & & & \\
\hline $\mathrm{EE}$ & 0.302 & 0.077 & 0.361 & 0.843 & & & & & & & \\
\hline $\mathrm{OP}$ & 0.041 & 0.061 & 0.418 & 0.263 & 0.927 & & & & & & \\
\hline $\mathrm{HM}$ & 0.093 & 0.081 & 0.396 & 0.213 & 0.259 & 0.904 & & & & & \\
\hline $\mathrm{AF}$ & 0.292 & 0.018 & 0.287 & 0.382 & 0.241 & 0.132 & 0.851 & & & & \\
\hline PE & 0.162 & 0.062 & 0.583 & 0.524 & 0.349 & 0.428 & 0.187 & 0.787 & & & \\
\hline AT & 0.313 & 0.028 & 0.393 & 0.421 & 0.205 & 0.171 & 0.683 & 0.311 & 0.853 & & \\
\hline SI & 0.021 & 0.047 & 0.391 & 0.240 & 0.431 & 0.332 & 0.036 & 0.393 & 0.081 & 0.855 & \\
\hline IN & 0.050 & 0.110 & -0.354 & -0.228 & -0.238 & -0.165 & -0.072 & -0.40 & -0.155 & -0.246 & 0.795 \\
\hline
\end{tabular}

Note: values on diagonal are square root of AVE 
Table 6. Hypothesis testing results

\begin{tabular}{lcccc}
\hline & $\begin{array}{c}\text { Path } \\
\text { Coeff. }\end{array}$ & Sig. & T Statistics & CI confirmation \\
\hline H1: PE $\rightarrow$ AIAI & 0.325 & $* * *$ & 6.557 & Yes \\
H2: EE $\rightarrow$ AIAI & -0.061 & ns & 1.210 & No \\
H3: SI $\rightarrow$ AIAI & 0.114 & $* *$ & 2.777 & Yes \\
H4: HM $\rightarrow$ AIAI & 0.115 & $* *$ & 2.954 & Yes \\
H5: $\mathrm{IN} \rightarrow$ AIAI & -0.138 & $* * *$ & 3.755 & Yes \\
H6: $\mathrm{UN} \rightarrow$ AIAI & 0.131 & $* * *$ & 3.637 & Yes \\
H7: $\mathrm{OP} \rightarrow$ AIAI & 0.151 & $* * *$ & 4.053 & Yes \\
H8: $\mathrm{AF} \rightarrow$ AIAI & 0.032 & ns & 0.631 & No \\
H9a: AF $\rightarrow$ AT & 0.681 & $* * *$ & 19.229 & Yes \\
H9b: AT $\rightarrow$ AIAI & 0.185 & $* * *$ & 3.522 & Yes \\
H10: GE $\rightarrow$ AIAI & 0.074 & $*$ & 1.933 & Yes \\
\hline
\end{tabular}

Note: ${ }^{*} \mathrm{p}<0.05 ;{ }^{* *} \mathrm{p}<0.01 ;{ }^{* * *} \mathrm{p}<0.00 ;$ ns: non-significant 


\section{Figure}

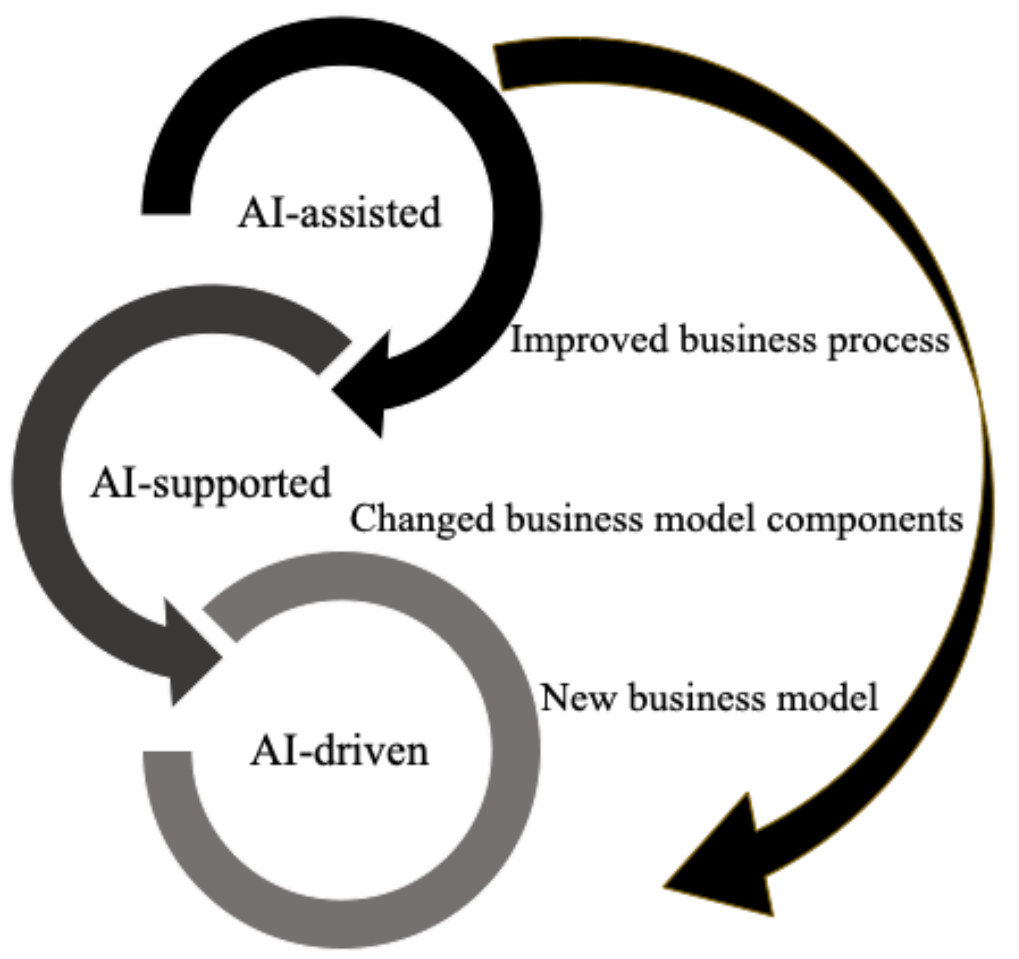

Figure 1. Increasing influence of AI in digital entrepreneurship 


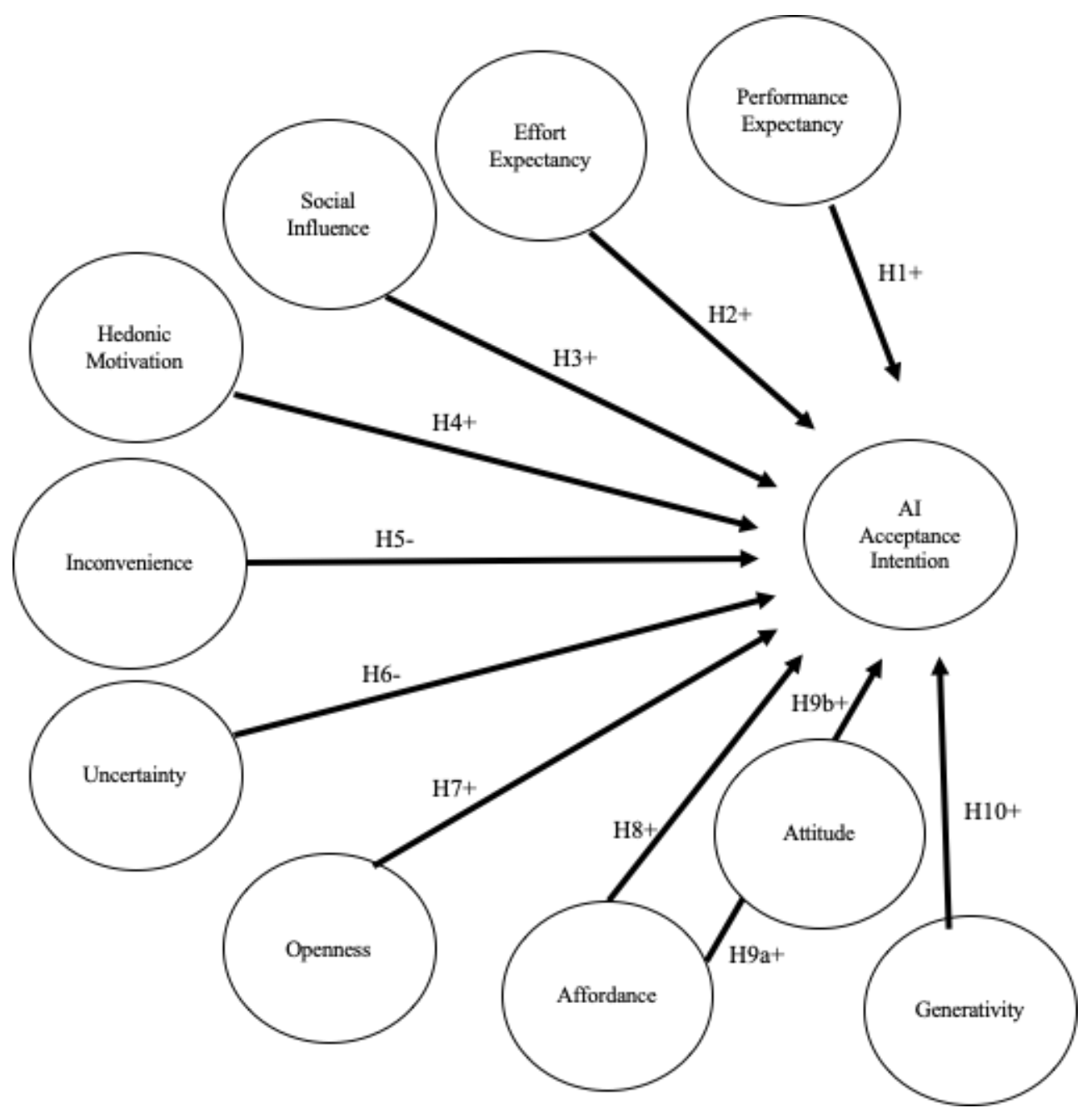

Figure 2. Artificial Intelligence Acceptance and Digital Entrepreneurship (AIADE) model 


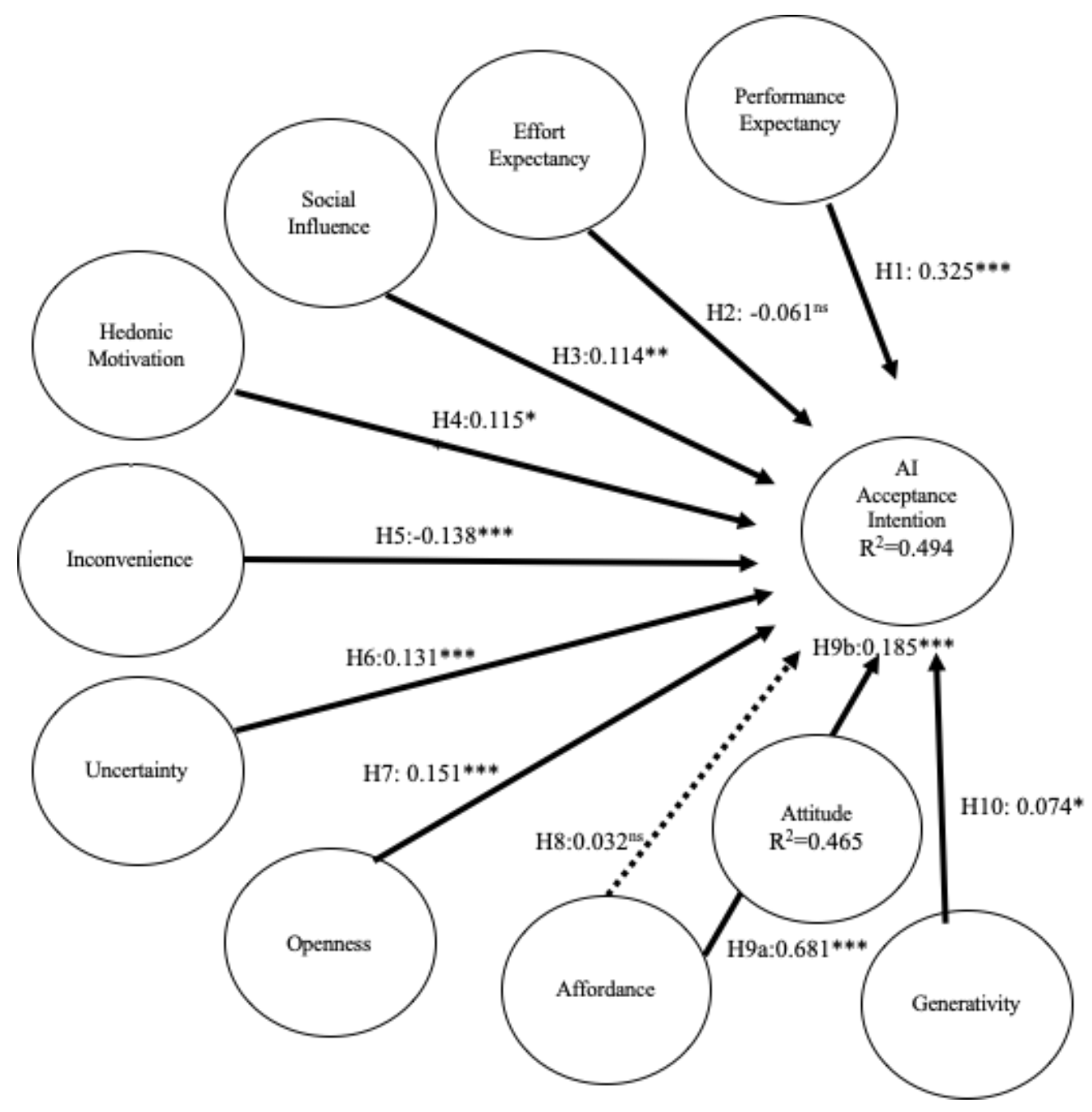

Figure 3. AI acceptance intention results ${ }^{*} \mathrm{p}<0.05 ; *{ }^{*} \mathrm{p}<0.01 ; * * * \mathrm{p}<0.00$; ns: non-significant 